\title{
Do MENA stock market returns follow a random walk process?
}

\author{
Salim Lahmiri*
}

Department of Computer Science, University of Quebec at Montreal, Montreal, Canada ESCA School of Management, Casablanca, Morocco

\section{H R O N I C L E}

\begin{tabular}{l}
\hline Article history: \\
Received September 242012 \\
Received in revised format \\
November 29 2012 2912 \\
Accepted November 292012 \\
Available online \\
29 November 2012 \\
\hline Keywords: \\
Stock Markets \\
Random Walk Hypothesis \\
Variance Ratio Test \\
MENA Region
\end{tabular}

\begin{abstract}
A B S T R A C T
In this research, three variance ratio tests; namely the standard variance ratio test, the wild bootstrap multiple variance ratio test, and the non-parametric rank scores test are adopted to test the random walk hypothesis (RWH) of stock markets in Middle East and North Africa (MENA) region using most recent data from January 2010 to September 2012. The empirical results obtained by all three econometric tests show that the RWH is strongly rejected for Kuwait, Tunisia, and Morocco. However, the standard variance ratio test and the wild bootstrap multiple variance ratio test reject the null hypothesis of random walk in Jordan and Kingdom of Saudi Arabia (KSA), while non-parametric rank scores test do not. We may conclude that Jordan and KSA stock market are weak efficient. In sum, the empirical results suggest that return series in Kuwait, Tunisia, and Morocco are predictable. In other words, predictable patterns that can be exploited in these markets still exit. Therefore, investors may make profits in such less efficient markets.
\end{abstract}

\section{Introduction}

The Efficient Markets Hypothesis (EMH) (Fama, 1970, 1998) states that current stock prices reflect all available information about individual stocks and about the stock market as well. In other words, stock prices adjust rapidly to the arrival of new information. Therefore, neither technical analysis, which is based on the study of historical prices nor fundamental analysis which is based on the analysis of financial information help investors predicting future prices. As a result, the EMH implies that stock returns are not forecastable; thus investors could not generate profits. The EMH is closely related to the concept of random walk hypothesis (RWH) that characterizes a price series where all subsequent price changes represent random departures from previous prices (Malkiel, 2003). In particular, the RWH is a straightforward approach to evaluate the predictability of stock returns, and the rejection of the RWH indicates that future returns can be predicted based on past prices. Indeed, the weak-form of the EMH implies that future equity prices are not predictable based on past prices.

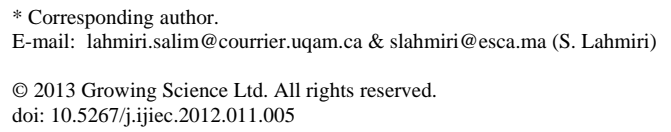


Since the work of Fama (1970), several studies have shown that stock price returns in the United States do not follow a random walk and are not normally distributed, including Fama and French (1988), Lo and MacKinlay (1988), and Mukherji (2011), among others. With the integration of international stock markets, the understanding of efficiency in emerging financial markets has become more important. Indeed, many recent studies examined the validity of the RWH in emergent economies including Brazil (Ely, 2011), Africa (Collins et al., 2011), China (Chong et al., 2012), India (Gupta and Basu, 2007), and Portugal (Borges, 2011). They reported unconformity with random walk hypothesis. Besides, a series of studies have contributed to the study of market efficiency in Middle East stock markets. For instance, Smith (2007) employed the variance ratio test (Lo and MacKinlay, 1988) methodology and found evidence of the RWH in Jordan. On the other hand, studies that present counter evidence include Al-Loughani (1995), Abraham et al. (2002), Al-Khazali et al. (2007), Smith (2007), and Al-Ajmi and Kim (2012) who rejected the RWH in Kuwait and Saudi Arabia based on the variance ratio test results. Table 1 provides an overview of previous works using data from the Middle East and North Africa (MENA) region.

\section{Table 1}

Overview of previous works in MENA region

\begin{tabular}{|c|c|c|c|}
\hline Studies & Countries & Period & Findings \\
\hline Al-Loughani (1995) & Saudi Arabia & $\begin{array}{l}27 \text { August } 1985 \\
\text { to } 1 \text { August } 1990\end{array}$ & RWH is rejected \\
\hline Abraham et al. (2002) & Bahrain, Kuwait, Saudi Arabia & $\begin{array}{l}7 \text { October } 1992 \text { to } 30 \\
\text { December } 1998\end{array}$ & $\mathrm{RWH}$ is rejected \\
\hline Al-Khazali et al. (2007) & Bahrain, Kuwait, Oman, Saudi Arabia. & October 1994 to December 2003 & RWH is rejected \\
\hline \multirow[t]{2}{*}{ Smith (2007) } & \multirow[t]{2}{*}{ Jordan, Lebanon, Kuwait, Oman } & \multirow[t]{2}{*}{ October 1996 to June 2003} & RWH is rejected for Jordan and Lebanon. \\
\hline & & & $\begin{array}{l}\text { RWH is not rejected for Kuwait and } \\
\text { Oman. }\end{array}$ \\
\hline Collins et al., (2011) & Morocco, Tunisia, Egypt (among others) & 2000 to 2007 & $\mathrm{RWH}$ is rejected \\
\hline \multirow[t]{3}{*}{ Al-Ajmi \& Kim (2012) } & \multirow[t]{3}{*}{$\begin{array}{l}\text { Abu Dhabi, Bahrain, Dubai, Kuwait, } \\
\text { Oman, Qatar and Saudi Arabia }\end{array}$} & $\begin{array}{l}\text { Abu Dhabi : } 1 \text { October } 2001 \text { to } 3 \\
\text { February } 2010\end{array}$ & RWH is rejected \\
\hline & & $\begin{array}{l}\text { Dubai: } 31 \text { December } 2003 \text { to } 3 \\
\text { February } 2010\end{array}$ & \\
\hline & & $\begin{array}{l}\text { Bahrain, Kuwait, Oman, Qatar, } \\
\text { Saudi Arabia: } 31 \text { December } 1999 \\
\text { to } 3 \text { February } 2010\end{array}$ & \\
\hline
\end{tabular}

The purpose of this study is to re-examine the RWH in North Africa and Middle East (MENA) stock markets using most recent data. Indeed, with recent international financial crisis and Arab Spring it would be interesting to shed light on the random walk behaviour in MENA region. The sample includes Morocco, Tunisia, Egypt, Jordan, Kuwait, and Saudi Arabia. The standard variance ratio test and its variants are used to determine whether stock price history information is fully reflected in current stock price.

The structure of this paper is as follows: Section 2 describes the econometric tests used in the study. Section 3 presents the data and the empirical results. Finally, Section 4 concludes this empirical work.

\section{Econometric approach}

The returns are computed as the logarithmic difference between two consecutive prices in a series. For instance, the returns $r_{t}$ are computed as follows:

$$
r_{t}=\log \left(p_{t}\right)-\log \left(p_{t-1}\right)
$$

where $p_{t}$ is the price at date $t$. This form of computing returns is a measure of continuously compounded rates of returns. More importantly, it allows de-trending the series and making them stationary. In other words, the obtained series $r_{t}$ are stationary.

\subsection{Variance ratio test}


The variance ratio test (VR) which is proposed by Lo and MacKinlay (1988) is the most popular econometric approach to check whether asset prices are predictable. The $V R$ is based on the premise that if the returns $r_{t}$ are purely random, then the variance of $k$-period return is $k$ times the variance of one-period return. Hence, under the null hypothesis that the returns follow a random walk, the variance ratio of $k$-differences $V R(k)$ should tends to unity, that is, the variance of the $k$-differences increases linearly with the difference $k$. the $V R$ is given by:

$\operatorname{VR}(k)=\frac{\sigma^{2}\left(r_{t}^{k}\right)}{\sigma^{2}\left(r_{t}^{1}\right)} \frac{1}{k}$

Lo and MacKinlay (1988) showed that if $r_{t}$ are independent and identically distributed (homoskedastic random walks), then under the null hypothesis that $V R(k)=1$, the test statistic $M_{\text {hom }}(r ; k)$ follows the standard normal distribution asymptotically. It is given by:

$M_{\text {hom }}(r ; k)=(V R(r ; k)-1)\left(\frac{2(2 k-1)(k-1)}{3 k T}\right)^{-0.5}$

where $T$ is the sample size. Since in general financial time series -including stock returns- exhibit conditional heteroskedasticity, Lo and MacKinlay (1988) proposed a heteroscedasticity robust test statistic $M_{\text {het }}(r ; k)$ which follows the standard normal distribution asymptotically under null hypothesis that $V R(k)=1$. It is given by:

$M_{\text {het }}(r ; k)=(V R(r ; k)-1)\left(\sum_{j=1}^{k-1}\left(\frac{2(k-j)}{k}\right)^{2} \delta_{j}\right)^{-0.5}$

where,

$\delta_{j}=\left\{\sum_{t=j+1}^{T}\left(r_{t}-\hat{\mu}\right)^{2}\left(x_{t-j}-\hat{\mu}\right)^{2}\right\} \div\left\{\left[\sum_{t=1}^{T}\left(r_{t}-\hat{\mu}\right)^{2}\right]^{2}\right\}$

and,

$\hat{\mu}=T^{-1} \sum_{t=1}^{T} r_{t}$

In this study, both the individual and joint versions of the $V R$ test are employed. The former tests the null hypothesis $V R(k)=1$ for a particular holding period, whilst the latter tests the null hypothesis over a number of different periods $(k)$.

\subsection{VR Wild bootstrap}

Kim (2006) suggested using the wild bootstrap technique (Mammen, 1993) to improve the small sample properties of variance ratio tests. In addition, this methodology eliminates the arbitrary choice of the holding periods $(k)$. The wild bootstrap algorithm is based on three stages:

a) Form a bootstrap sample of $T$ observations $r_{t}^{*}=\eta_{t} r_{t}(t=1, \ldots T)$ where $\eta$ is a random sequence with zero mean and unit variance.

b) Calculate $M_{\text {het }}^{*}(r ; k)$ which is $M_{\text {het }}(r ; k)$ given in equation (4) but obtained from the bootstrap sample generated in stage (a).

c) Repeat (a) and (b) many times to form a bootstrap distribution of the test statistic $M_{\text {het }}^{*}(r ; k)$.

The bootstrap distribution of $M_{h e t}^{*}(r ; k)$ is used to approximate the sampling distribution of the $M_{\text {het }}(r ; k)$ given in equation (4). The $p$-value of the test can be estimated as the proportion of $M_{\text {het }}^{*}(r ; k)$ greater than the statistic $M_{\text {het }}(r ; k)$ calculated from the original data. In this study, the 
number of replications is set to 1000. Finally, as suggested by Kim (2006) the standard normal distribution is used for $\eta$.

\subsection{Rank scores}

Wright (2000) proposed a run test to check whether successive returns are independent as should happen under the null hypothesis of a random walk. Let $s\left(r_{t}\right)$ be the rank of the return series $r_{t}$ among all $T$ values. Then, the standardized rank score $s_{1 t}$ (with sample mean zero and sample variance 1 ) and Van Der Waerden rank score $s_{2 t}$ (with sample mean zero and sample variance approximately 1 ) are defined as follows:

$s_{1 t}=\left(s\left(r_{t}\right)-(T+1) 2^{-1}\right)\left(\sqrt{(T-1)(T+1) 12^{-1}}\right)^{-1}$

$s_{2 t}=\Phi^{-1}\left(s\left(r_{t}\right)(T+1)^{-1}\right)$

where, $\Phi$ is the standard normal cumulative distribution function of a random variable $x$. it is given by:

$\Phi(x)=\int_{-\infty}^{x} f(t) d t$

The test is based on the statistic $R_{1}$ under the null hypothesis of homoskedastic random walks, and the statistic $R_{2}$ under the null hypothesis of heteroskedastic random walks. The statistics $R_{1}$ and $R_{2}$ are defined as follows:

$R_{1}=\left(\frac{(T k)^{-1} \sum_{t=k+1}^{T}\left(s_{1 t}+s_{1 t-1}+\ldots+s_{1 t-k}\right)^{2}}{T^{-1} \sum_{t=1}^{T} s_{1 t}^{2}}-1\right) \times\left(2(2 k-1)(k-1)(3 k t)^{-1}\right)^{-0.5}$

and,

$R_{2}=\left(\frac{(T k)^{-1} \sum_{t=k+1}^{T}\left(s_{2 t}+s_{2 t-1}+\ldots+s_{2 t-k}\right)^{2}}{T^{-1} \sum_{t=1}^{T} s_{1 t}^{2}}-1\right) \times\left(2(2 k-1)(k-1)(3 k t)^{-1}\right)^{-0.5}$

As shown in Wright (2000), these statistics follow an exact distribution under the assumption that $\operatorname{VR}(k)=1$.

\section{Data and empirical results}

The dataset used in the econometric analysis includes stock market prices of Jordan from January $3^{\text {th }}$ 2010 to September $19^{\text {th }} 2012$, Kuwait from January $3^{\text {th }} 2010$ to May $10^{\text {th }} 2012$, Kingdom of Saudi Arabia (KSA) from January $2^{\text {th }} 2010$ to September $17^{\text {th }} 2012$, Tunisia from January $4^{\text {th }} 2010$ to December $30^{\text {th }} 2011$, and the Moroccan Madex price index from January $4^{\text {th }} 2010$ to September $17^{\text {th }}$ 2012. Fig. 1 exhibits the price level of each stock market. The results for the random walk tests using the variance ratio $(V R), V R$ using wild bootstrap, and rank scores are presented in Table 1 (Jordan, Kuwait, KSA), and Table 2 (Tunisia, Morocco). 
The null hypothesis is that the returns (differences of log prices) follow a random walk. All tests are applied to the whole sample (joint test) and also for arbitrarily chosen $k=2,4,8,16$. For convenience, only variance ratios and their respective $p$-values are provided. All tests are conducted based on the hypothesis that all stock returns in all markets exhibit conditional heteroskedasticity. Thus the appropriate statistics are computed; particularly those given in equations (4) and (11). This assumption is more realistic and leads to valid statistics.
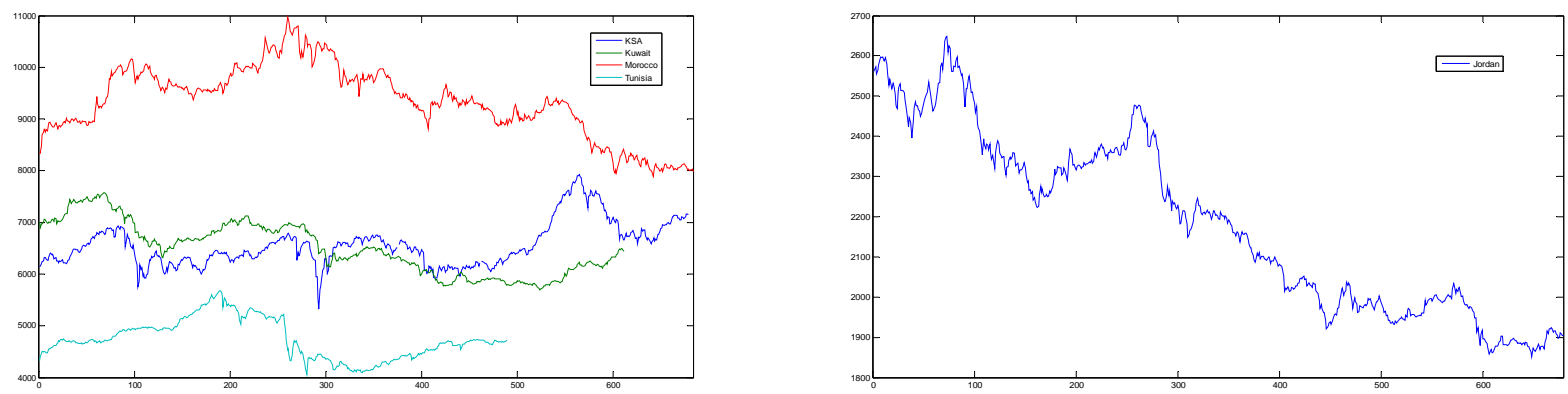

Fig. 1. Stock market price levels since January 2010. The $x$-axis refers to observations

Table 1

Variance ratio test results for Jordan, Kuwait, and KSA

\begin{tabular}{|c|c|c|c|c|c|c|c|c|}
\hline Jordan & & & Kuwait & & & KSA & & \\
\hline VR & & & VR & & & VR & & \\
\hline $\begin{array}{l}\text { Individual } \\
\text { Tests }\end{array}$ & & & $\begin{array}{l}\text { Individual } \\
\text { Tests }\end{array}$ & & & $\begin{array}{l}\text { Individual } \\
\text { Tests }\end{array}$ & & \\
\hline$k$ & $\begin{array}{c}\text { Variance } \\
\text { Ratio }\end{array}$ & Probability & $k$ & $\begin{array}{c}\text { Variance } \\
\text { Ratio }\end{array}$ & Probability & $k$ & $\begin{array}{c}\text { Variance } \\
\text { Ratio }\end{array}$ & Probability \\
\hline 2 & 1.105742 & 0.0209 & 2 & 1.175344 & 0.0058 & 2 & 1.060694 & 0.3756 \\
\hline 4 & 1.194571 & 0.0227 & 4 & 1.313691 & 0.0037 & 4 & 1.090255 & 0.5444 \\
\hline 8 & 1.250291 & 0.0587 & 8 & 1.384072 & 0.0149 & 8 & 1.072535 & 0.7490 \\
\hline 16 & 1.300827 & 0.1167 & 16 & 1.684735 & 0.0026 & 16 & 1.068562 & 0.8216 \\
\hline Joint Tests & & & Joint Tests & & & Joint Tests & & \\
\hline & Value & Probability & & Value & Probability & & Value & Probability \\
\hline & 2.310487 & 0.0809 & & 3.006342 & 0.0105 & & 0.886070 & 0.8480 \\
\hline Bootstrap & & & Bootstrap & & & Bootstrap & & \\
\hline $\begin{array}{l}\text { Individual } \\
\text { Tests }\end{array}$ & & & $\begin{array}{l}\text { Individual } \\
\text { Tests }\end{array}$ & & & $\begin{array}{c}\text { Individual } \\
\text { Tests }\end{array}$ & & \\
\hline$k$ & $\begin{array}{c}\text { Variance } \\
\text { Ratio }\end{array}$ & Probability & $k$ & $\begin{array}{c}\text { Variance } \\
\text { Ratio }\end{array}$ & Probability & $k$ & $\begin{array}{c}\text { Variance } \\
\text { Ratio }\end{array}$ & Probability \\
\hline 2 & 1.105742 & 0.0220 & 2 & 1.175344 & 0.0010 & 2 & 1.060694 & 0.4140 \\
\hline 4 & 1.194571 & 0.0220 & 4 & 1.313691 & 0.0020 & 4 & 1.090255 & 0.5690 \\
\hline 8 & 1.250291 & 0.0620 & 8 & 1.384072 & 0.0110 & 8 & 1.072535 & 0.7640 \\
\hline 16 & 1.300827 & 0.1180 & 16 & 1.684735 & 0.0020 & 16 & 1.068562 & 0.8150 \\
\hline Joint Tests & & & Joint Tests & & & Joint Tests & & \\
\hline & Value & Probability & & Value & Probability & & Value & Probability \\
\hline & 2.310487 & 0.0590 & & 3.006342 & 0.0030 & & 0.886070 & 0.6940 \\
\hline $\begin{array}{l}\text { Rank } \\
\text { score }\end{array}$ & & & $\begin{array}{l}\text { Rank } \\
\text { score }\end{array}$ & & & $\begin{array}{l}\text { Rank } \\
\text { score }\end{array}$ & & \\
\hline $\begin{array}{c}\text { Individual } \\
\text { Tests }\end{array}$ & & & $\begin{array}{c}\text { Individual } \\
\text { Tests }\end{array}$ & & & $\begin{array}{l}\text { Individual } \\
\text { Tests }\end{array}$ & & \\
\hline$k$ & $\begin{array}{c}\text { Variance } \\
\text { Ratio }\end{array}$ & Probability & $k$ & $\begin{array}{c}\text { Variance } \\
\text { Ratio }\end{array}$ & Probability & - & $\begin{array}{c}\text { Variance } \\
\text { Ratio }\end{array}$ & Probability \\
\hline 2 & 1.104386 & 0.0080 & 2 & 1.157043 & 0.0000 & 2 & 1.111419 & 0.0030 \\
\hline 4 & 1.192797 & 0.0100 & 4 & 1.287344 & 0.0000 & 4 & 1.182811 & 0.0100 \\
\hline 8 & 1.240856 & 0.0430 & 8 & 1.337220 & 0.0030 & 8 & 1.258819 & 0.0210 \\
\hline 16 & 1.259357 & 0.1370 & 16 & 1.517131 & 0.0030 & 16 & 1.233311 & 0.2330 \\
\hline Joint Tests & & & Joint Tests & & & Joint Tests & & \\
\hline & Value & Probability & & Value & Probability & & Value & Probability \\
\hline & 2.718049 & 0.0210 & & 3.881864 & 0.0010 & & 2.892610 & 0.0070 \\
\hline
\end{tabular}


As show in Table 2, the random walk hypothesis (RWH) is rejected at the $5 \%$ significance level for Jordan using all tests for $k=2,4,8$, but not for $k=16$. In addition, only the ranks score joint test rejects the null hypothesis at the $5 \%$ significance level. For Kuwait, all categories of tests (both individuals and joints) strongly reject the null hypothesis of RWH at 5\% significance level. Finally, based on individual and joint tests the empirical tests show that both the variance ratio $(V R)$ and the $V R$ using wild bootstrap tests do not reject the null hypothesis of the random walk for KSA at 5\% significance level. However, the RWH hypothesis is not rejected at $5 \%$ significance level using individual and joint ranks scores tests, except for $k$ set to16. Finally, empirical results in Table 3 show that the random walk hypothesis is rejected at the $5 \%$ significance level for Morocco using all tests for $k=2,4$, but not for $k=8,16$. In addition, all joint tests strongly reject the null hypothesis of $\mathrm{RWH}$ at the $5 \%$ significance level. For Tunisia, all categories of tests (both individuals and joints) strongly reject the null hypothesis of random walk at $5 \%$ significance level, except the standard $V R$ and $V R$ using bootstrap test for $k$ set to 8 and 16.

Table 2

Variance ratio test results for Tunisia and Morocco

\begin{tabular}{|c|c|c|c|c|c|}
\hline Tunisia & & & Morocco & & \\
\hline VR & & & VR & & \\
\hline Individual Tests & & & Individual Tests & & \\
\hline$k$ & Variance Ratio & Probability & $k$ & Variance Ratio & Probability \\
\hline 2 & 1.318173 & 0.0103 & 2 & 1.190559 & 0.0006 \\
\hline 4 & 1.558186 & 0.0101 & 4 & 1.254939 & 0.0098 \\
\hline 8 & 1.547668 & 0.0748 & 8 & 1.072561 & 0.6163 \\
\hline 16 & 1.342079 & 0.3948 & 16 & 1.054837 & 0.7819 \\
\hline \multirow[t]{3}{*}{ Joint Tests } & & & Joint Tests & & \\
\hline & Value & Probability & & Value & Probability \\
\hline & 2.574001 & 0.0396 & & 3.417480 & 0.0025 \\
\hline Bootstrap & & & Bootstrap & & \\
\hline Individual Tests & & & Individual Tests & & \\
\hline$k$ & Variance Ratio & Probability & $k$ & Variance Ratio & Probability \\
\hline 2 & 1.318173 & 0.0080 & 2 & 1.190559 & 0.0000 \\
\hline 4 & 1.558186 & 0.0040 & 4 & 1.254939 & 0.0050 \\
\hline 8 & 1.547668 & 0.0590 & 8 & 1.072561 & 0.6110 \\
\hline 16 & 1.342079 & 0.4010 & 16 & 1.054837 & 0.7780 \\
\hline \multirow[t]{2}{*}{ Joint Tests } & & & Joint Tests & & \\
\hline & $\begin{array}{c}\text { Value } \\
2.574001 \\
\end{array}$ & $\begin{array}{c}\text { Probability } \\
0.0340\end{array}$ & & $\begin{array}{c}\text { Value } \\
3.417480 \\
\end{array}$ & $\begin{array}{c}\text { Probability } \\
0.0000\end{array}$ \\
\hline Rank score & & & Rank score & & \\
\hline Individual Tests & & & Individual Tests & & \\
\hline$k$ & Variance Ratio & Probability & $k$ & Variance Ratio & Probability \\
\hline 2 & 1.260728 & 0.0000 & 2 & 1.166421 & 0.0000 \\
\hline 4 & 1.448221 & 0.0000 & 4 & 1.231595 & 0.0000 \\
\hline 8 & 1.488679 & 0.0000 & 8 & 1.058190 & 0.6160 \\
\hline 16 & 1.576135 & 0.0000 & 16 & 1.043974 & 0.8040 \\
\hline \multirow{3}{*}{ Joint Tests } & & & Joint Tests & & \\
\hline & Value & Probability & & Value & Probability \\
\hline & 5.759676 & 0.0000 & & 4.349302 & 0.0000 \\
\hline
\end{tabular}

In sum, the empirical results show that the stock returns in Kuwait, Tunisia and Morocco do not follow a random walk based on all joint tests; thus they are predictable. On the other hand, the stock returns in Jordan and KSA follow a random walk based on $V R$ and $V R$ using wild bootstrap tests. Thus they are not predictable according to the joint form of these tests. However, the $p$-values of the rank scores test indicate that stock returns in Jordan and KSA do not follow a random walk; thus they are predictable according to this test. In general, like recent studies (Collins et al., 2011; Al-Ajmi \& Kim, 2012) that 
used post-2010 data, our findings show that return series are generally predictable in MENA stock markets; particularly for Kuwait, Tunisia, and Morocco.

\section{Conclusion}

The random walk hypothesis (RWH) is useful to test the predictability of stock returns in the context of weak-form efficiency of financial markets. Therefore, the rejection of the RWH indicates that past prices can be used to predict future returns. The variance ratio $(V R)$ test is adopted to test the RWH in five stock markets of MENA region; namely Jordan, Kuwait, Kingdom of Saudi Arabia (KSA), Tunisia, and Morocco. Three variants of the VR test are considered including the Lo-MacKinlay's (1988) standard variance ratio test, Kim's (2006) wild bootstrap multiple variance ratio test, and Wright's (2000) non-parametric rank scores. The empirical results show strong evidence of two findings. First, stock returns in Kuwait, Tunisia, and Morocco stock markets are predictable. In other words, investors may use past prices to predict future returns and make profits in these market. Second, the null hypothesis of random walk is rejected in Jordan and KSA. This result indicates that stock markets in Jordan and KSA are weak-form efficient.

\section{References}

Abraham, A., Seyyed, F., \& Alsakran, S. (2002). Testing the random walk behavior and efficiency of the Gulf stock markets. The Financial Review, 37, 469-80.

Al-Ajmi, J., \& Kim, J.H. (2012). Are Gulf stock markets efficient? Evidence from new multiple variance ratio tests. Applied Economics, 44 (4), 1737-1747.

Al-Khazali, O., Ding, D., \& Pyun, C. (2007). A new variance ratio test of random walk in emerging markets: a revisit. The Financial Review, 42, 303-317.

Al-Loughani, N.E. (1995). Random walk in thinly traded stock markets: the case of Kuwait. Arab Journal of Administrative Sciences, 3, 198-209.

Borges, M.R. (2011). Random walk tests for the Lisbon stock market. Applied Economics, 43 (5), 631639.

Chong, T.T.-L., Lam, T.-H., \& Yan, I.K.-M. (2012). Is the Chinese stock market really inefficient? China Economic Review, 23, 122-137.

Collins, G.N, Opong, K.K., Danbolt, J., \& Dewotor, F.S. (2011). Testing the weak-form efficiency in African stock markets. Managerial Finance, 37 (3), 195-218.

Ely, R.A. (2011). Returns predictability and stock market efficiency in Brazil. Rev. Bras. Finanças, Rio de Janeiro, 9 (4), 571-584.

Fama, E. (1970). Efficient capital markets: a review of theory and empirical work. Journal of Finance, 25 (2), 383-417.

Fama, E. (1998). Market efficiency, long-term returns, and behavioral finance. Journal of Financial Economics, 49 (3), 283-306.

Fama, E., \& French, K. (1988). Permanent and temporary components of stock prices. Journal of Political Economy, 96, 246-73.

Gupta, R., Basu, P.K. (2007). Weak form efficiency in Indian stock markets. International Business \& Economics Research Journal, 6 (3), 57-64.

Kim, J.H. (2006). Wild bootstrapping variance ratio tests. Economics Letters, 92, 38-43.

Lo, A.W., \& MacKinlay, A.C. (1988). Stock market prices do not follow random walks: evidence from a simple specification test. The Review of Financial Study, 1, 41-66.

Malkiel, B.G. (2003). The efficient market hypothesis and its critics. Journal of Economic Perspectives, 17 (1), 59-82.

Mammen, E. (1993). Bootstrap and wild bootstrap for high dimensional linear-models. The Annals of Statistics, 21, 255-85.

Mukherji, S. (2011). Are stock returns still mean-reverting? Review of Financial Economics, 20, 22-27. 
172

Smith, G. (2007). Random walks in Middle Eastern stock markets. Applied Financial Economics, 17, 587-96.

Wright, J. (2000). Alternative variance-ratio tests using ranks and signs. Journal of Business and Economics Statistics, 18, 1-9. 